\title{
The Acquisition of the Passive Alternation by Kuwaiti EFL Learners
}

\author{
Abdullah M. Alotaibi ${ }^{1} \&$ Hashan Alajmi ${ }^{2}$ \\ ${ }^{1}$ Assistant Prof at PAAET \& CBE, Kuwait \\ ${ }^{2}$ Associate Prof at Department of English, College of Art, Kuwait University, Kuwait \\ Correspondence: Abdullah M. Alotaibi, P. O. Box 66821, 43759 Bayan, The State of Kuwait. Tel: \\ 965-9962-1499. E-mail: alotaibi917@gmail.com or otaiby2013@gmail.com
}

Received: October 31, 2014 Accepted: November 22, 2014 Online Published: January 27, 2015

doi:10.5539/ijel.v5n1p44 URL: http://dx.doi.org/10.5539/ijel.v5n1p44

\begin{abstract}
This study attempts to test whether fifty advanced Kuwaiti EFL learners have acquired the English passive alternation. To this end, the researchers used a Grammaticality Judgment Task (GJT) to check whether the participants would be able to distinguish between alternating and non-alternating verbs. The verbs used in the test were chosen based on their frequency in the Corpus of Contemporary American English (COCA). The results reveal that positive transfer from L1 played a big role in the participants' correct answers on the test, especially with regard to the verbs that passivise. Additionally, the participants may have provided wrong answers on the GJT due to their unfamiliarity with some of the verbs. However, the participants faced various difficulties with the verbs that do not passivise. These difficulties could be ascribed to over-generalising the passivisation rule, or confusing the non-causative with the passive construction. Their overall score suggests that they have not acquired the English passive alternation (total mean=45\%). The study concludes with some recommendations for further research.
\end{abstract}

Keywords: syntax, passive-active alternation, argument structure, second language acquisition, theta roles, Arab EFL learners

\section{Introduction}

In his discussion of the famous learnability problem known as "Baker's paradox", Pinker $(1989$, p. 8) outlined four different lexico-syntactic alternations that exhibit the same learnability problem found in Baker's paradox. These four alternations include the locative alternation, dative alternation, causative alternation, and passive alternations. Table 1 below demonstrates these four types:

Table 1. Four types of lexico-syntactic alternations outlined by Pinker (1989)

\begin{tabular}{lll}
\hline Type of alternation & Alternating & Non-alternating \\
\hline Locative & Sarah stuffed rice into the chicken & Layla poured coffee into the cup \\
& Sarah stuffed the chicken with rice & *Layla poured the cup with coffee \\
Dative & Sam told a story to Mary & Mike reported the crime to the police \\
& Sam told Mary a story & *Mike reported the police the crime \\
I closed the window & the girl cried \\
the window closed & *the boy cried the girl \\
Passive & John kicked the ball & Mary resembles her mother \\
& The ball was kicked by John & *Mary is resembled by her mother
\end{tabular}

Coppock (2009, p. 1) explained that Baker's paradox revolves around three presuppositions, namely: (1) productive patterns have exceptions that are viewed as arbitrary; (2) productive generalisations do exist; and (3) unavailability of negative evidence i.e., ungrammatical evidence of a particular sentence type. More specifically, Coppock (2009, p. 1) indicated that a pattern is seen as productive if there is an unlimited number of items which can manifest that pattern. For example, an unlimited number of verbs can be used in the double-object structure found in dative verbs, such as Sam told Mary a story. Therefore, it can be seen that a certain pattern is productive if a newly coined word can be used to manifest that pattern. However, in reality, productive patterns do have arbitrary exceptions. For instance, despite being qualified to be used in the dative construction with the 
preposition to i.e., Mike reported the crime to the police, other dative verbs such as report, which has a similar meaning to told, are seen as odd in a double-object structure i.e., *Mike reported the police the crime. In other words, it can be noticed that some verbs are eligible to be in some constructions while others do not, even if the outcome is completely logical (Pinker, 1989). It can be argued that investigating the acquisition of these lexico-syntactic alternations by first and second language learners can elicit conclusions that may shed light on the area of language acquisition. In particular, testing whether second language learners can differentiate between verbs that alternate and verbs that do not may be an area worthy of further investigation. Little attention has been given to the acquisition of the English passive alternation by EFL/ESL learners, and the difficulties that they may encounter in distinguishing between verbs that alternate and verbs that do not. Hence, this study aims to test whether advanced Kuwaiti EFL learners have acquired the English passive alternation.

\section{Literature Review}

\subsection{Overview}

It can be observed that the dative alternation has drawn much attention in the last few decades compared to the other three types (see table 1). Adopting a theory of markedness, Mazurkerwich (1984) investigated the acquisition of dative alternation in English by second language learners. The markedness theory assumes that unmarked structures; parts of the core grammar are usually acquired prior to marked ones; parts of the peripheral rules. The data was elicited from French and Inuktitut ESL learners on the one hand and from English speakers on the other using a judgment test. Mazurkerwich (1984) argued that verbs in the prepositional construction are regarded as the unmarked structure, whereas verbs in the double-object construction are seen as the marked structure. The findings showed that Mazurkerwich's (1984) hypothesis was confirmed i.e., the unmarked constructions were acquired first. In another study, Woods (2012) examined the acquisition of the dative alternation by German-English bilingual and English monolingual children, showing the differences between the two groups. The acquisition of the locative alternation has also been studied by several researchers. For instance, Twomey et al. (2013) conducted a corpus analysis of the English locative alternation (see table 1) to investigate the verb classes in children and adults. To offer a solution to the long unresolved issue of how children acquire these classes, they assumed that distributional regularities in the linguistic input can provide enough evidence for the emergence of verb classes and how they become connected to certain constructions. They suggested that distributional regularities in the input can support these classes which, in turn, support a distributional approach to learning the meanings of verbs.

On the other hand, little consideration has been given to the acquisition of the dative alternation by EFL learners. Several studies have been conducted to test children's ability to distinguish between verbs that alternate and those that do not (e.g., Bladie, 1976; Kirby, 2010). However, to the best of the researchers' knowledge, no study has been conducted to examine the acquisition of the English passive alternation by Kuwaiti EFL learners. This suggests that this area can elicit fruitful results. The next section provides an overview of the English passive alternation.

\subsection{Passive Alternation}

Argument structures refer to the information that determines the ways by which a verb's arguments are encoded in the syntax (Pinker, 1989, p. 71). For instance, the verb beat has two arguments as seen in the following example:

\section{1) a. Germany beat Argentina in the world cup.}

The first argument is the subject noun phrase (NP) Germany, and the second is the NP Argentina, functioning as the direct object. If we are to change example (1) into the passive voice, the result can be seen below:

2) b. Argentina was beaten by Germany in the world cup

It can be noticed that several processes are required to change the verb from the active voice to the passive. Firstly, the morphology of the verb is affected (was beaten), the verb beat is accompanied by the auxiliary be. Passive verbs are distinguished from other types of verbs, specifically, an affix is usually added to the verb which changes its morpho-syntactic category; the verb becomes a participle rather than finite. Secondly, the subject Germany is no longer the subject of the sentence. Instead, it appears as an adjunct prepositional phrase (PP) headed by the preposition by. Thirdly, the former direct object Argentina has now become the subject of the sentence in the passive voice (Haegeman, 1991).

It has been observed that verbs that passivise tend to be actional; this means that these verbs have a subject (agent) and object (patient). An example of an actional verb can be seen below: 
3) Mary a cake
(Agent)
(patient)

On the contrary, stative verbs cannot be passivised (Haegeman, 1991). The following are some examples:

4) a. *two hundred and twenty pounds is weighed by Sam

b. *nine is equalled by four plus five

However, the difference between verbs that passivise and verbs that do not is not as simple as distinguishing between stative and nonstative verbs or transitive and nontransitive verbs. For example, in some cases the underlying object of the sentence can be idiomatic i.e., the hatchet was buried. In other cases, it can be existential i.e., it was thought to be snowing. In addition, not all transitive verbs passivise. For instance, it is ungrammatical to say the girl was escaped by the boy's advances, even though the verb escape can be used transitively. In addition, some verbs such as rumour only appear in the passive i.e., Sam is rumoured to be a killer. Thus, it is ungrammatical to say *she rumoured Sam to be a killer. Therefore, another constraint on passivisation was proposed by Jackendoff (1972). He posited that there should be semantic constraints on the types of argument which the verb normally takes. In particular, he indicated that in order for a verb to passivise, the thematic relations should be arranged as follows:

Theme source/goal/location agent

In particular, pinker (1989, p. 91) explained that the following thematic role is created by a passive rule:

$\mathrm{X}$ (theme) is in the circumstance characterised by Y's (agent) acting on it.

The subject of the passive sentence should hold a higher position than the object of $b y$, this condition is referred to as the Thematic Hierarchy Condition (THC). In the passive, the subject should be a theme. For instance, in the sentence John was hit by Sam, John is the one who is affected by the action i.e., hitting, which means that it is the theme. The object of $b y$, on the other hand, has lost its high status as a core argument and has become implicit (Jackendoff, ibid). This can be due to the fact that one can say John was hit; thus, deleting by Sam altogether. Therefore, if one takes a look back at the ungrammatical sentences in (4), one can see that they violate the THC. The location or the goal is mapped onto the subject, whereas the theme is mapped onto the object of by (Jackendoff, ibid). The quality or quantity of one entity is in comparison with a standard. This is because in these examples, the entity functions as a theme, whilst the standard functions as a figurative location. This can be explained more clearly if the measurement expressions can be used as locative or goal prepositions in other structures i.e., four and five is equal to nine and Sam weighs in at two hundred and twenty pounds. This condition also excludes sentences such as *Mary is resembled by her mother. The latter can be due to the fact that her mother is a goal, which can be seen if we changed the construction of the sentence and used a preposition i.e., Mary's resemblance to her mother (Jackendoff, ibid). Similarly, the THC rules out verbs like escape since in a sentence like Mary escaped from John, John is the source; hence, it cannot be passivised. In sum, it can be observed that there is a semantic condition which the verb has to meet to be able to passivise. As mentioned previously, the acquisition of the English passive alternation by EFL learners has been given little attention compared to other types of alternation. Thus, this study aims to provide answers to the following questions:

1) To what extent have fifty advanced Kuwaiti EFL learners acquired the English passive alternation?

2) Do they face problems with certain types of verbs? If so, why?

The next section provides a description of the methodology.

\section{Methodology}

\subsection{The Sample}

Fifty students at the Public Authority of Applied Education and Training (PAAET) and College of Basic Education (CBE) participated in the study. Their mean age was 22 years old. They were all native speakers of Kuwaiti Spoken Arabic (KSA). The participants were selected randomly, and they were chosen based on their scores on English Placement Test (EPT). Specifically, only those who scored 70-85 were chosen to participate in the study. It should be noted that the participants have studied English at public schools in Kuwait for 12 years and finished two main English courses at the CBE, namely, E 161 and E 261. These courses tackle the issue of passive alternation in English. The researchers opted for this age group based on their belief that the participants at this level would have acquired the English passive alternation. 


\subsection{The Test}

The participants were given a Grammaticality Judgment Task (GJT) in English. This instrument was used by other researchers (e.g., Mazurkerwich, 1984; Woods, 2012) to investigate other types of alternation, such as the dative alternation. The two researchers deemed the GJT reliable to test the participants' knowledge of different types of alternation as it elicits fruitful results and deep insight into the participants' answers. The participants were asked to write a tick next to the sentence they thought to be grammatical and a cross next to the ones they thought to be ungrammatical (see Appendix A). The number of verbs used in the sentences in the GJT was 21: 10 verbs that passivise, another 10 that do not, and one inchoative verb that was used ungrammatically as a distracter. The verbs selected can be seen below:

- Ten nonalternating verbs (verbs that do not passivise):

Lack, resemble, equal, escape, weigh, cost, sleep, arrive, belong, and marry

- $\quad$ Ten alternating verbs (verbs that passivise):

Beat, build, made, complete, eat, protect, smash, steal, paint, and lose

- One inchoative verb used ungrammatically:

Disappear

The verbs used in the GJT were selected based on their frequency in the COCA. The purpose for this procedure was to ascertain the occurrence of these verbs in contemporary speech. Table 2 below shows the frequency of the selected verbs in the COCA.

Table 2. The frequency of the selected verbs in the Corpus of Contemporary American English (COCA)

\begin{tabular}{lll}
\hline & Verbs & Frequency in the COCA \\
\hline Verbs that passivise & Beat & 40405 \\
build & 43240 \\
made & 337264 \\
complete & 41695 \\
eat & 44254 \\
protect & 44254 \\
smash & 2139 \\
steal & 6656 \\
paint & 21552 \\
lose & 39415 \\
\hline Verbs that do not passivise & lack & 43163 \\
& resemble & 3737 \\
& equal & 22480 \\
escape & 17806 \\
& weigh & 5221 \\
& cost & 70327 \\
sleep & 40550 \\
& arrive & 11577 \\
belong & 8929 \\
marry & 10369 \\
\hline
\end{tabular}

Table 2 clearly shows that the selected verbs are quite frequent in the COCA. This means that these verbs occur frequently in contemporary speech. Hence, it can be argued that by this level of English proficiency, the participants should be aware of the meanings of these verbs. With regard to the alternating verbs, each one appeared in a grammatical sentence. As for the non-alternating verbs, each one appeared in an ungrammatical sentence. Together with the distracter, the GJT consisted of 21 sentences (see Appendix A). In order to test the validity of this tool, the researchers gave the test to 3 native speakers of British English. They confirmed that the tool is reliable. With respect to ethical issues, the participants agreed to take part in the current study voluntarily. They were also informed that their data will be protected and their personal information will not be disclosed to any other person. At the end, the researchers thanked the participants for their cooperation and helpfulness. The next section provides the results and discusses them. 


\section{Results and Discussion}

As mentioned previously, this study aims to investigate the extent to which fifty advanced Kuwaiti EFL learners can differentiate between verbs that passivise such as:

5) The dinner was made by Sarah

And verbs that do not passivise such as:

6) *Three shelves were contained by the cupboard

Generally, the results showed that the participants have not acquired the English passive alternation (total mean $=45 \%$ ). The results demonstrated that the participants encountered major difficulties with the verbs that do not passivise. In other words, they considered sentences like *Sue is resembled by her sister grammatically correct. This shows that the participants may have lacked the ability to distinguish between the verbs that alternate between the active and passive and those that do not. Table 3 below demonstrates the number and percentage of correct answers with regard to the verbs that passivise on the GJT.

Table 3. The number and percentage of the verbs that do passivise on the GJT

\begin{tabular}{lll}
\hline Verbs that do passivise & $\begin{array}{l}\text { Number of correct answers on the } \\
\text { GJT }\end{array}$ & $\begin{array}{l}\text { Percentage of correct answers on the } \\
\text { GJT }\end{array}$ \\
\hline Beat & 43 & $86 \%$ \\
build & 42 & $84 \%$ \\
made & 41 & $82 \%$ \\
complete & 23 & $46 \%$ \\
eat & 46 & $92 \%$ \\
protect & 31 & $62 \%$ \\
smash & 22 & $44 \%$ \\
steal & 36 & $72 \%$ \\
paint & 29 & $58 \%$ \\
lose & 21 & $42 \%$ \\
Total mean & 33 & $67 \%$ \\
\hline
\end{tabular}

Table 3 shows that on the verbs that alternate, the participants' performance on the test was satisfactory to some degree (total mean $=67 \%$ ). The participants scored the highest percentage on the verb eat $(92 \%)$; 46 participants out of 50 answered it correctly (see table 3). However, the participants scored the lowest percentage of correct answers on the verb lose (42\%); only 21 out of 50 provided the correct answer. Table 3 also shows that the participants also scored high on other verb such as beat (86\%), build (84\%), and made (82\%). It can be argued that the participants were able to identify many verbs that passivise and judge them as correct because they were familiar with them, and may have used them in their life enough times not to make mistakes. In fact, these verbs are very frequent in the COCA as well (see table 2). For instance, the verbs beat, build, and made occur 40405, 43240, and 337264 times in the COCA respectively. In addition, it can be argued that the participants scored the highest percentages of correct answers on the verbs that also passivise in Kuwaiti Spoken Arabic (KSA). Hence, it can be claimed that positive transfer from L1 had a big role to play in the participants' correct answers. Positive transfer from L1 can be defined as transferring a structure from L1 to L2 in which this structure is deemed correct (Saville-Troike, 2012). For example, one may argue that the participants transferred the following structure from L1 to L2:

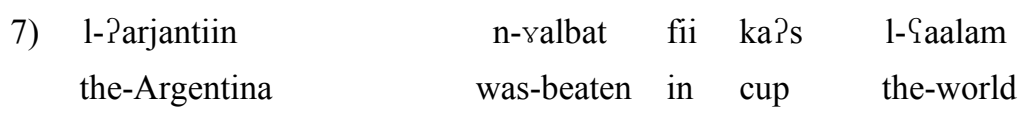

'Argentina was beaten in the world cup'

It should be noted that this sentence was used in the GJT (see Appendix A), it appeared as follows:

\section{Argentina was beaten by Germany in the world cup}

Based on example (7), it can be seen that the passive in KSA is formed by adding a prefix $n$ - to the verb as in $n$-salbat; thus, the verb morphology is changed (cf. Pinker, 1989). Additionally, the former subject of the active sentence in KSA does not appear as the object of by as is the case in English. On the contrary, the former subject is deleted. Example (7) shows that the participants may have translated the verb literally from L1 to L2; hence, they were able to provide the correct answer on the test. The fact that English happens to accept such a structure 
does not mean that the participants have acquired the English passive alternation; they may have been merely lucky. Another example which shows that positive transfer from L1 contributed to the participants' correct answers on the test is the following:
8) 1-jisir
n-banaa
the-bridge
was-built

'the bridge was built'

Again, the same example was used on the GJT (see Appendix A), it appeared as follows:

7. The bridge was built by 600 workers

On the other hand, the participants' answers on some verbs were not as good. For example, only $42 \%$ of the participants provided correct answers on the verb lose on the GJT. One may argue that the participants provided wrong answers with respect to the verb lose because it does not passivise in KSA. Example (9) below demonstrates this fact:

9) * mujawharaath-aa n-daaৎat

Jewellery-hers was-lost

'her jewellery was lost'

Thus, it can be argued that negative transfer from L1 to L2 is the cause for the participants' low percentage of correct answers. Negative transfer refers to the transfer of a structure from L1 to L2 in which this structure is deemed faulty (Saville-Troike, 2012). Finally, table 3 shows that only $44 \%$ of the participants provided correct answers on the verb smash, despite the fact that it passivises in KSA. This can be seen in example (10) below:
10) 1-kaasih n-kasrat
the-glass was-broken
'the glass was broken'

It can be argued that the participants were not familiar with this verb. Hence, they provided wrong answers on the test.

With respect to the verbs that do not passivise, table 4 shows the number and percentage of correct answers with respect to the verbs that do not passivise.

Table 4. The number and percentage of correct answers on the verbs that do not passivise

\begin{tabular}{lll}
\hline Verbs that do not passivise & $\begin{array}{l}\text { Number of correct answers on the } \\
\text { GJT }\end{array}$ & $\begin{array}{l}\text { Percentage of correct answers on the } \\
\text { GJT }\end{array}$ \\
\hline lack & 10 & $20 \%$ \\
resemble & 12 & $24 \%$ \\
equal & 15 & $30 \%$ \\
escape & 17 & $34 \%$ \\
weigh & 9 & $18 \%$ \\
cost & 8 & $16 \%$ \\
sleep & 7 & $14 \%$ \\
arrive & 4 & $8 \%$ \\
belong & 14 & $28 \%$ \\
marry & 19 & $38 \%$ \\
Total mean & 12 & $23 \%$ \\
\hline
\end{tabular}

Table 4 shows that on the verbs that do not alternate, the participants' performance on the test was very low (total mean $=23 \%$ ) compared to their performance on the alternating verbs (total mean=67\%). The participants scored the highest percentage on the verb marry (38\%); 19 participants out of 50 answered it correctly. However, the participants scored the lowest percentage of correct answers on the verb arrive (8\%); only 4 out of 50 provided the correct answer. It can be claimed that the participants may have confused another structure with the passive, namely, the non-causative structure. This may explain their low percentage of correct answers on verbs, such as arrive (8\%), sleep (14\%), and belong (28\%). Example (11) below provides more insight into this justification: 


\section{1) d-dyuuf wisluu \\ the-guests arrived \\ 'the guests arrived'}

Example (11) shows that the participants may have not been aware of the difference between non-causative verbs and passive verbs. The verb arrive is an intransitive verb, which means that this verb cannot be passisived. However, the participants considered a sentence such as the following as correct (see Appendix A):

15. The singers were arrived yesterday

It can be seen that the participants may have over-generalised the passivisation rule to consider examples like (15) above correct. This may be due to the fact that both the non-causative and passive construction lack an object i.e., the singers arrived yesterday. The similarity between the two structures may have caused the participants to confuse them on the GJT. Table 4 also shows that the participants provided wrong answers on verbs, such as lack $(20 \%)$, weigh $(18 \%)$, cost $(16 \%)$, resemble $(24 \%)$, equal $(30 \%)$, and marry $(38 \%)$ on the GJT. It can be argued that the participants have also over-generalised the passivistion rule with respect to these verbs. This can be due to the fact that these verbs can be used transitively. The following examples demonstrate this fact:

12) The players lacked the motivation

13) Sam weighs two hundred and twenty pounds

14) This pen costs two dollars

15) Nine equals five plus four

16) Sue resembles her sister

17) Bill married Jennifer

Therefore, it can be claimed the participants passivised the above sentences as a result of over-generalisation of the passivisation rule. Hence, they considered the following sentences correct on the GJT (see Appendix A):

16. The motivation was lacked by the players

19. Two hundred and twenty pounds is weighed by Sam

4. Two dollars are cost by this pen

8. Nine is equalled by five plus four

10. Sue is resembled by her sister

\section{Jennifer was married by Bill}

In sum, the participants were not aware of the fact that not all transitive verbs can be passivised. Thus, they passivised the above-mentioned verbs on the GJT.

\section{Conclusion and Recommendation}

This study examined whether fifty advanced Kuwaiti EFL learners can differentiate between the verbs that passivise and those that cannot. Using a Grammaticality Judgement Task (GJT), the results showed that the participants have not acquired the English passive alternation (total mean=45\%). They also showed that the participants' performance on the verbs that passivise was satisfactory to some extent (total mean=67\%). The researchers argued that positive transfer from L1 played a major role in the participants' performance. However, it was argued that since these verbs passivise in L1 and the participants just transferred the structure from L1 to L2, this may not mean that they have acquired that particular structure. The results also showed that the participants' performance on the verbs that do not passivise was very low (total mean $=23 \%$ ) in comparison with their performance on the verbs that do passivise (total mean=67\%). These results can be ascribed to over-generalising the passivisation rule. Possibly, the participants were not aware of the fact that not all transitive verbs passivise. Also, the participants may have confused the passive with the non-causative construction due to the similarities between these two syntactic structures. On the basis of these results, it is recommended that EFL teachers need to pay more attention to passivisation in class. Students need to be aware of the differences between the passive and non-causative constructions. More studies on the acquisition of other types of alternation need to be conducted to shed light on the acquisition process of argument structure in English.

\section{References}

Bladie, B. (1976). The acquisition of the passive voice. Journal of Child Language, 3, 331-348. 
http://dx.doi.org/10.1017/S0305000900007224

Coppock, E. (2009). The logical and empirical foundations of Baker's paradox. PhD thesis. Stanford University, Stanford, California.

Haegeman, L. (1991). Introduction to government and binding theory. Oxford: Blackwell Publishers.

Jackendoff, R. (1972). Semantic interpretation in generative grammar. Cambridge: MIT Press.

Kirby, S. (2010). Passives in first language acquisition: What causes the delay?. University of Pennsylvania Working Papers in Linguistics, 16, 109-117.

Mazurkerwich, I. (1984). The acquisition of the dative alternation by second language learners and linguistic theory. Language Learning, 34, 91-108. http://dx.doi.org/10.1111/j.1467-1770.1984.tb00997.x

Pinker, S. (1989). Learnability and cognition: The acquisition of argument structure. Cambridge: MIT Press.

Saville-Troike, M. (2012). Introducing second language acquisition (2nd ed.). Cambridge: MIT Press. http://dx.doi.org/10.1017/CBO9780511888830

Twomey, K., Chang, F., \& Ambridge, B. (2013). A distributional learning account of the acquisition of the locative alternation: Corpus analysis and modeling. In Proceedings of the 35th Annual Conference of the Cognitive Science Society (pp. 1498-1503). Cognitive Science Society, Austin, TX.

Woods, R. (2012). Dative alternation and its acquisition by German-English bilingual and English monolingual children. Unpublished MA thesis, University of York, York.

\section{Appendix A}

\section{Grammaticality Judgment Task}

Read the following sentences. Put a tick $(\checkmark)$ next to any sentence you think grammatical and a cross $(X)$ next to any sentence you think ungrammatical. Your first decision is the one we want. Please do not change your answers.

\begin{tabular}{clc}
\hline 1. & The poor dolphin was eaten by the shark & $\checkmark$ \\
2. & The baby is slept by his mother & $\times$ \\
3. & Argentina was beaten by Germany in the world cup & $\times$ \\
4. & Two dollars are cost by this pen & $\checkmark$ \\
5. & Jennifer was married by Bill & $\checkmark$ \\
6. & The tasks were completed by the student & $\times$ \\
7. & The bridge was built by 600 workers & $\checkmark$ \\
8. & Nine is equalled by five plus four & $\times$ \\
9. & The singer is protected by her bodyguard & $\times$ \\
10. & Sue is resembled by her sister & $\checkmark$ \\
11. & The thief disappeared the gold from the police & $\times$ \\
12. & The Mona Lisa was painted by Leonardo da Vinci & $\checkmark$ \\
13. & The book is belonged by Sarah & $\times$ \\
14. & The money was stolen by the robber & $\times$ \\
15. & The singers were arrived yesterday & $\checkmark$ \\
16. & The motivation was lacked by the players & $\checkmark$ \\
17. & Four plates were smashed by Bill & $\times$ \\
18. & Her jewellery was lost in the airport & $\checkmark$ \\
19. & Two hundred and twenty pounds is weighed by Sam & $\times$ \\
20. & The strawberry cake was made by Layla & The tiger was escaped by the hunter \\
21. & &
\end{tabular}




\section{Appendix B}

\section{Arabic Sounds}

\begin{tabular}{|c|c|c|}
\hline Arabic consonants/vowels & Symbols & Description \\
\hline$\therefore$ & ? & voiceless glottal stop \\
\hline ب & $\mathrm{b}$ & voiced bilabial stop \\
\hline$ت$ & $\mathrm{t}$ & voiceless dento-alveolar stop \\
\hline$\stackrel{1}{ث}$ & $\theta$ & voiceless inter-dental fricative \\
\hline ج & $\mathrm{j}$ & voiced post-alveolar affricate \\
\hline$\tau$ & $\underline{\mathrm{h}}$ & voiceless pharyngeal fricative \\
\hline$\dot{\tau}$ & $\mathrm{x}$ & voiceless uvular fricative \\
\hline د & $\mathrm{d}$ & voiced dento-alveolar stop \\
\hline$\dot{~}$ & ð & voiced alveolar fricative \\
\hline ر & $\mathrm{r}$ & voiced alveo-palatal trill \\
\hline j & $\mathrm{z}$ & voiced alveolar fricative \\
\hline س & $\mathrm{s}$ & voiceless alveolar fricative \\
\hline 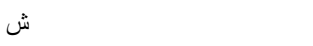 & $\int$ & voiceless alveo-palatal fricative \\
\hline ص & $\underline{\mathrm{s}}$ & voiceless alveolar emphatic fricative \\
\hline 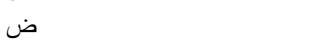 & $\overline{\mathrm{d}}$ & voiced alveolar emphatic stop \\
\hline b & $\underline{t}$ & voiceless dento-alveolar emphatic stop \\
\hline ظ & $\underline{\partial}$ & voiced alveolar emphatic fricative \\
\hline$\varepsilon$ & $\varsigma$ & voiced pharyngeal fricative \\
\hline$\dot{\varepsilon}$ & $\gamma$ & voiced uvular fricative \\
\hline ف & $\mathrm{f}$ & voiceless labio-dental fricative \\
\hline ق & $\mathrm{q} / \mathrm{g}$ (Note 2$)$ & voiceless/voiced uvular stop \\
\hline ك & $\mathrm{k}$ & voiceless velar stop \\
\hline J & 1 & voiced alveolar lateral \\
\hline 5 & $\mathrm{m}$ & voiced bilabial nasal \\
\hline ن ن & $\mathrm{n}$ & voiced alveolar nasal \\
\hline 。 & $\mathrm{h}$ & voiceless glottal fricative \\
\hline g & $\mathrm{w}$ & voiced labio-velar glide \\
\hline ي & $\mathrm{y}$ & voiced palatal glide \\
\hline il & $\mathrm{a}$ & low short central unrounded \\
\hline 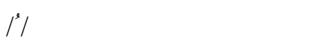 & $\mathrm{u}$ & high short back rounded \\
\hline 1.1 & $\mathrm{i}$ & high short front unrounded \\
\hline i & aa & low long central unrounded \\
\hline وو & uu & high long back rounded \\
\hline يب & ii & high long front unrounded \\
\hline 9 & o: & mid long back rounded \\
\hline 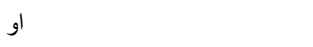 & aw & low short front unrounded + labio-velar glide \\
\hline اي & ay & low short front unrounded + palatal glide \\
\hline يبي & ee & mid long front unrounded \\
\hline
\end{tabular}

\section{Notes}

Note 1. For the reader's convenience, Appendix B provides a key for Arabic sounds.

Note 2. These symbols represent the voiceless and voiced uvular stop.

\section{Copyrights}

Copyright for this article is retained by the author(s), with first publication rights granted to the journal.

This is an open-access article distributed under the terms and conditions of the Creative Commons Attribution license (http://creativecommons.org/licenses/by/3.0/). 